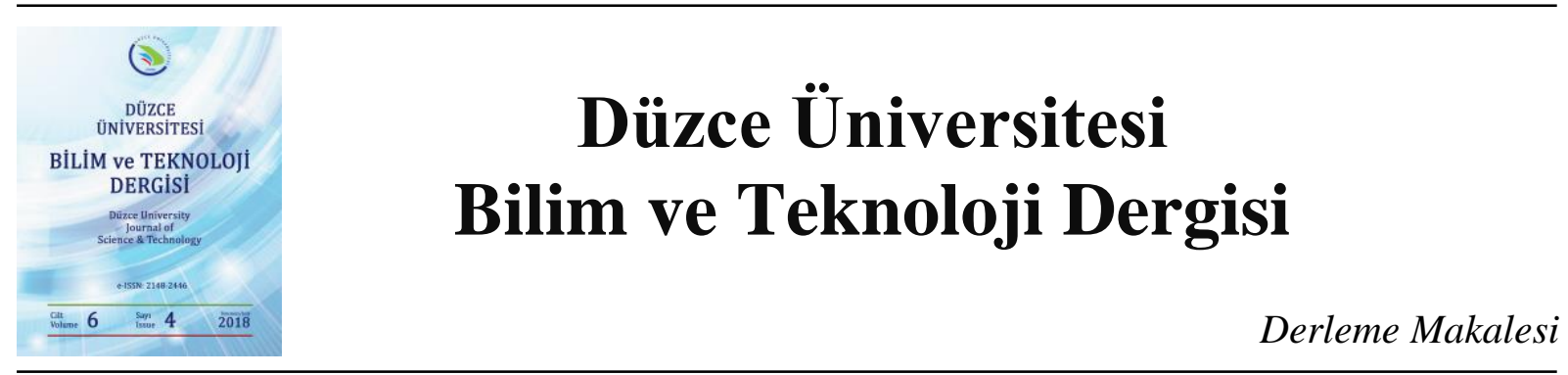

\section{Hibrit Çim Uygulama Yönteminin Futbol Sahası Örneğinde İncelenmesi}

\author{
Hüseyin ÖGÇE ${ }^{a, *}, M$. Kıvanç AK ${ }^{\text {b }}$ \\ ${ }^{a}$ Peyzaj Mimarlı̆̆ $\breve{g}_{l}$ Anabilim Dalı,, Fen Bilimleri Enstitüsü, Düzce Üniversitesi, Düzce, TÜRKİYE \\ ${ }^{b}$ Peyzaj Mimarlı̆̆ Bölümü, Orman Fakültesi, Düzce Üniversitesi, Düzce, TÜRKIYYE \\ * Sorumlu yazarin e-posta adresi: mehmetkivancak@duzce.edu.tr
}

\begin{abstract}
ÖZET
Çim alanlar, insanoğlunun dış mekânlarda gösterdiği rekreasyonel aktivitelerde görsel zenginliğinin yanı sıra fonksiyonel işlevleri ile de uzun zamandır çalışma konusu olarak araştırmalara dâhil olmuştur. Dış mekân rekreasyonel aktivitelerinde sıkça karşımıza çıkan çim alanlar, özellikle spor sahalarının vazgeçilmez bir parçasıdır. Futbol, bu aktivitelerin en başında gelen spor dalı olarak yüzyıllardır hâkimiyetini korumaktadır. Günümüzde futbol, bu sporu icra edenler için bir meslek, takip edenler açısından ise bir tutku anlamına gelmektedir. Bu sporun en önemli gösteri yerleri de futbol sahaları ya da stadyumlardır. Kaliteli ve zevk veren futbol oyununun icrası için gerekli unsurların başında ise; sağlıklı ve futbola elverişli müsabaka alanları gelmektedir. Sağlıklı ve elverişli bir futbol sahasının tesis edilebilmesi için de çim zeminin homojen ve tekdüze bir yapıya sahip olması son yıllarda futbol oyunun vazgeçilmez bir unsuru haline gelmiştir. 19. Yüzyılda başlayan ve 20. Yüzyılda devam eden el ile çim tohumu ekme işlemi, 1990'lı yıllarda hibrit çim teknolojisinin geliştirilmeye başlanması ile farklı bir boyut kazanmıştır. Hibrit çim teknolojisinin en yaygın kullanım alanları ise kuşkusuz futbol sahaları olarak görülmektedir. Bu bağlamda bu çalışma; çim ve hibrit çim tanımlarını, hibrit çim özelliklerini, hibrit çim bileşenlerini, hibrit çim ile oluşturulmuş futbol sahalarının diğer çim alan tesis tekniklerine göre avantajları ile dezavantajlarını ve özellikle futbol sahalarında hibrit çim uygulama aşamasının ne şekilde gerçekleştirildiğini ortaya koymaktadır.
\end{abstract}

Anahtar Kelimeler: Çim, çim alanlar, hibrit çim, futbola sahası.

\section{Investigation of Hybrid Grass Application Method on Football Pitch}

\begin{abstract}
$\underline{\text { ABSTRACT }}$
Turf areas are included in research articles for a long time because of their visual richness and functional properties. These sort of areas are seen frequently in places where outdoors human activity are made and constitute essential part of sport areas. Football is maintained its dominance for centuries as the top sporting activity of these activities. Nowadays, football is a profession for those who perform this sport and is passion for followers also. The most important demonstration places of this sport are football fields or stadiums. Football needs healthy and proper football pitches for quality and pleasure playing. Homogeneous color and uniform
\end{abstract}


texture has become indispensable form for establishment of football pitches in the recent years. The process of composing turf areas, which started in the 19th century and continued in the 20th century, has gained a different stage with a development of hybrid grass technology in 1990's. The most common uses of hybrid grass technology are football pitches undoubtedly. In summary, this paper includes grass and hybrid grass definitions, hybrid grass features, hybrid grass components, advantages and disadvantages of hybrid grass techniques compared with other turf pitches techniques and also application process of hybrid grass techniques on football pitches especially.

Keywords: Grass, grass areas, hybrid grass, football pitch

\section{GiRIS}

Cim; toprağı kavrama özelliği yüksek, yüzeyi örten, yere çok yakın bitkilerdir[1]. Başlıca çim türleri; Lolium(İngiliz çimi), Festuca(Yumak), Poa(Çayır salkım otu), Agrostis(Tavus otu) ve sıcak iklime dayanıklılığı ile bilinen Cynodon(Bermuda) ve Paspalum(Yalancıdarı) çim türleridir. Lolium çim türü, serin iklime adapte olabilen ve uygun koşullarda diğer çim türlerine oranla erken çimlenme ve kaplama özelliği gösteren bir türdür[2].

Çim alanlar, peyzaj alanlarına olumlu görsel etkilerinin yanı sıra; sosyal, fiziksel ve ekonomik değerler katmaktadırlar[3]. Bu tür alanlar yaşadığımız çevredeki en önemli bitkisel öğeyi oluşturmakla birlikte, insana estetik kalite sunma ve insanın aktif dinlenme mekânları olma gibi üstün özelliklere sahip alanlardır. Bu bağlamda çim alanların tesisi önem arz etmektedir. Çim alanların tesisi her ne kadar zevkli olsa da gerek tesis aşamasında, gerekse bakım aşamasında yoğun uğraş gerektiren çalışmalardır[4]. Çim alan tesisi uygulamasında kullanılan yöntemlerin önde gelenleri; ekme çim, hydroseeding ve serme rulo çim uygulamalarıdır.

Kentlerde günden güne artan yoğun ve yorucu stres insanoğlunu etkilemektedir. Bunun sonucunda insanoğlu serbest zamanlarını daha kaliteli geçirmeyi istemektedir[5]. Günümüzde spor olgusunun önüne geçen futbol organizasyonu[6], insanın serbest zaman faaliyetlerini değerlendirdikleri oluşumların öncülerindendir ve kimileri için bir tutku kimileri içinse rekreasyon ya da turizm aktivitesi haline bürünmüş bir oluşumdur. Bu durumun bir getirisi olarak futbol sahalarındaki çim yüzeyinin görsel kalitesi, izleyiciler ve oyuncular üzerinde olumlu veya olumsuz etkiler yaratmaktadır. Bu görsel kalite etkilerinin önde gelenleri renk uyumu, doku uyumu ve tekdüzeliktir[4]. Renk ve doku uyumu görsel kaliteyi artırmadaki önemli hususlardandır[7]. Çeşitli nedenlerden ötürü çim üzerinde meydana gelen bozulmalar, renk ve doku uyumunu bozmakta ve bu bozulma neticesinde kullanıcıların görsel kalitesi olumsuz etkilenmektedir.

Futbol sahaları, futbol oyununun güzelliğini ve kalitesini artıran[8] en temel yapı taşlarındandırlar. $\mathrm{Bu}$ sporu icra edenler için sahanın oyun elverişliliğinin, izleyiciler için ise görsel kalitenin yüksek seviyede olması önem arz etmektedir[9]. 1970'li ve 1980'li senelerde her ne kadar sahalar çim yüzey örtüsü ile kaplı olsalar da, yağmur yağması durumunda drenaj sistemlerinin yetersizliği nedeniyle saha balçık haline dönmekteydi[10]. Drenaj sistemlerinin geliştirilmesi ile birlikte bu olumsuz durumun neden olduğu durumlar azalış gösterse de etkin ve elverişli futbol oyunu için tesis edilmesi gereken 
alanlarda nihai netice alınamamıştır. Bu nedenle sahaların tesisi için gerekli olan teknolojinin günden güne gelişim içerisinde olduğu görülmektedir.

Son zamanlarda futbol sahalarının tesisi için üç temel yüzey malzemesi kullanılmaktadır. Bunlar; \%100 doğal çimden oluşturulmuş yüzeyler, \%100 suni çimden oluşturulmuş yüzeyler ve hem doğal hem de yapay bileşenlere sahip olan hibrit çim yüzeyleridir. Doğal çim sahaları için genel olarak kabul edilen maksimum haftalık oyun süresi 8,5 saat/haftadır[11] ve bu tür sahalar müsabaka sonrasında çim yüzeyinde olumsuz hasarların çok görüldüğü kullanımlardır. \%100 suni çim yüzeyleri 1960'lı yılların ortalarında geliştirildiğinden beri birçok farklı amaçla kullanılmış olsalar da[12,13] barındırdığı yapaylık hissi, aşırı 1sı tutma[14] ve sıcak havalarda kötü kauçuk kokusu yayma gibi olumsuz etkileri mevcuttur. $\mathrm{Bu}$ olumsuz durumları giderilmesi ve müsabaka sahasının görsel kalitesi ve oyun elverişliliği gibi olumlu etkilere katkı sağlamak adına 1990'lı yıllarda[12] hibrit çim teknolojisi geliştirilmiş ve sahalarda uygulanmaya başlanmıştır.

\section{HiBRit Çim NEDiR?}

Türk Dil Kurumu(TDK) sözlügüne göre hibrit; melez anlamına gelmektedir. Futbol sahalarında bir uygulama yöntemi olarak hibrit çim metodunda ise durum biraz farklıdır. Hibrit çim tanımı, iki farklı doğal çim türünün melezlenmesi sonucu oluşturulmuş yeni bir çim türü anlamına gelmekle birlikte çalışmanın asıl konusu olan hibrit çim sahaları; doğal çim dokusunun, polipropilen olarak adlandırılan[12] sentetik çim bileşenleri ile desteklenmesi suretiyle oluşturulmuş alanlar özelinde kullanılan bir ifadedir(Şekil1, Şekil2 ve Şekil3). Bu tür sahalar FIFA tarafindan, sentetik malzeme ile güçlendirilmiş doğal zemin olarak tanımlanmakta[11] ve ilk uygulama örneklerine 1990'lı yıllarda rastlanmaktadır[15]. Günümüzde örneklerine sıkça rastladığımız hibrit çim sahaların kullanım alanlarının önde gelenlerini; futbol, golf ve rugby sahaları oluşturmakta[16] ve ayrıca amerikan futbolu ve beyzbol sahalarında da tercih edilmektedir[8]. Oyuncu sağlı̆̆ı açısından da hibrit çim zeminine sahip müsabaka sahaları, oldukça güvenli alanlardır[17]. Bu tipteki sahaların tesisi için firmalar belirli aşamalardan geçip Uluslararası Futbol Federasyonu(FIFA) tarafından uygulama sertifika belgesi alabilmektedirler[18].

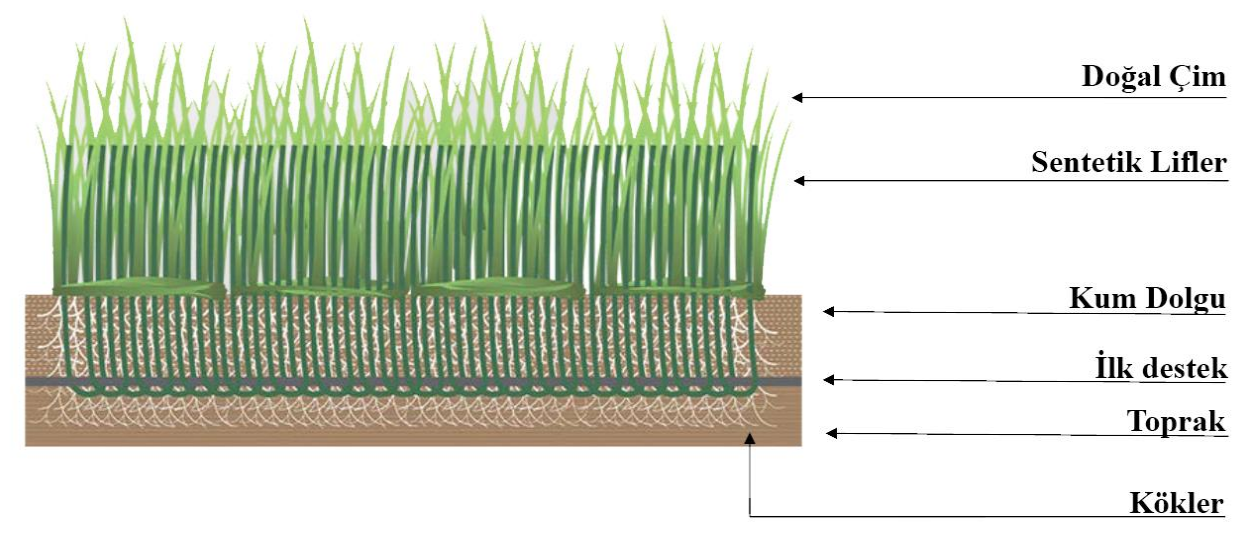

Şekil 1. Hibrit Çim Zemin Kesiti [19] 


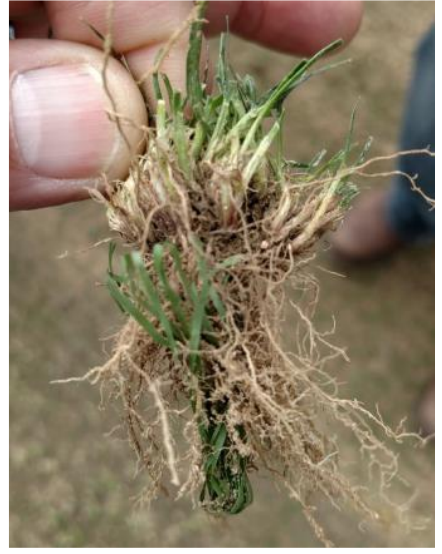

Şekil 2. Hibrit Çim Örneği[21]

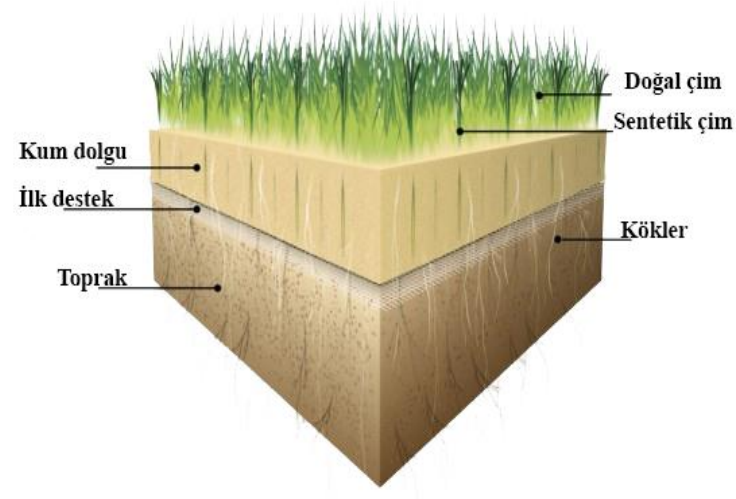

Şekil 3. Hibrit Çim Perspektif [19]

\section{Futbol Sahalarinda Hibrit Çim Uygulama TeKNiKLERI}

Hibrit çim uygulama yöntemlerinin tesis safhasına geçilmeden önce sahanın belirli aşamalardan geçirilip hazırlanması gerekmektedir. Bu aşamalar;

1. Drenaj sistemlerinin hazırlanmas1,

2. Isitma sisteminin tesisi,

3. Serilecek toprağın tesviyesi ile eğim düzeylerinin ayarlanmasıdır.

Uygulama sahasının ön hazırlık evresi \%100 doğal çim saha tesis aşamaları gibidir. Temelde üç tip hibrit çim uygulama yöntemi mevcuttur. İlki; yerinde tohumlama yöntemi, ikincisi; rulo hibrit çim yöntemi[19], üçüncüsü ise; sonradan hibrit[16] yöntemidir.

\section{A. YERINDE TOHUMLAMA YÖNTEMI}

Ön hazırlık safhasının ardından yüzey, tohumlama işlemi için hazır hale gelmektedir. Tohumlama işlemini oluşturan unsurlar; yapay malzemenin serimi, kumlama, furçalama ve tohumlama aşamalarıdır. Bu işlemde saha, 7-8 haftalık bir süreç sonrası kullanıma hazır hale gelmektedir[19].

Yapay malzemenin serimi: Bu aşamada tesviye edilmiş toprak üzerine geçirgen bir malzemeye(ilk destek) sabit olan yapay çim lifleri serilmektedirler(Şekil 4 ve Şekil 5).

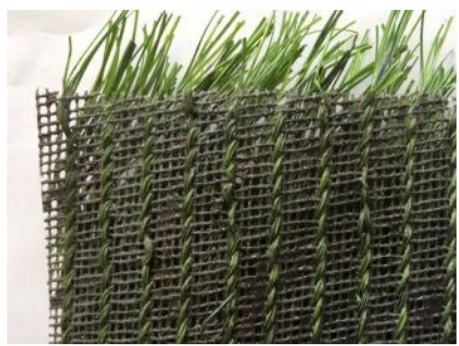

Şekil 4. Sentetik Lifler[21]

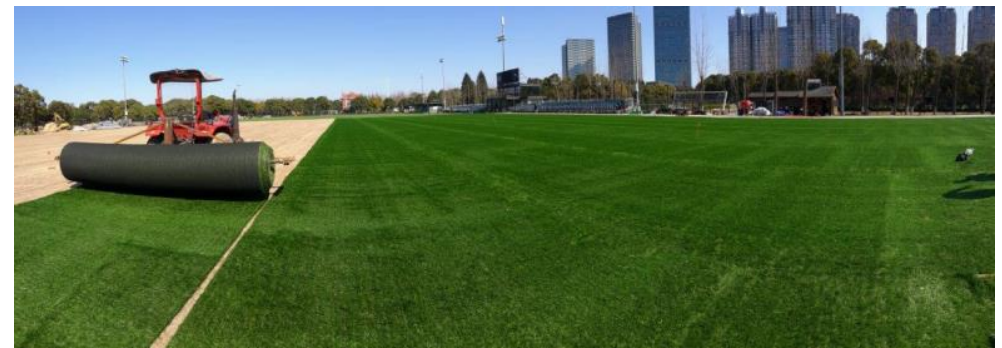

Şekil 5. Sentetik Liflerin Serim Işslemi[19] 
Kumlama: Serim işleminden sonra drenaj kabiliyetinin üst düzeyde tutulması adına içinde organik madde bulunan bir miktar kumlama işlemi yapılmaktadır(Şekil 6).

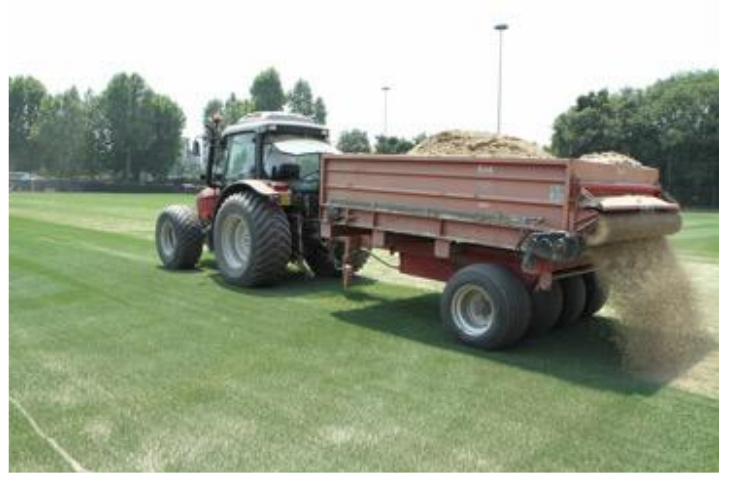

Şekil 6. Kumlama [19]

Firçalama: Kumun homojen dağılması ve alt toprak zemini ile bütünleşmesi için furçalama işlemi yapılmaktadır (Şekil 7).

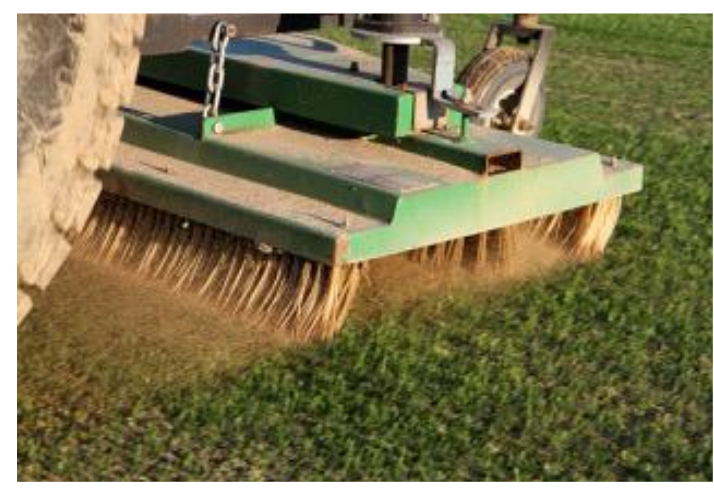

Şekil 7. Firçalama işlemi[19]

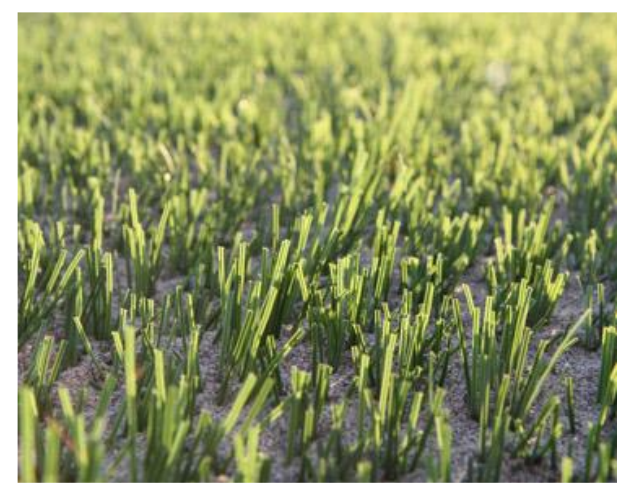

Şekil 8. Fırçalama sonrası görünüm[19]

Tohumlama: Tüm bu işlemlerin ardından makineler tarafından tohumlama işlemi gerçekleştirilmektedir(Şekil 9). Seçilecek çim tohumlarının türleri, uygulama alanındaki iklim verilerine göre değişiklik göstermektedir.

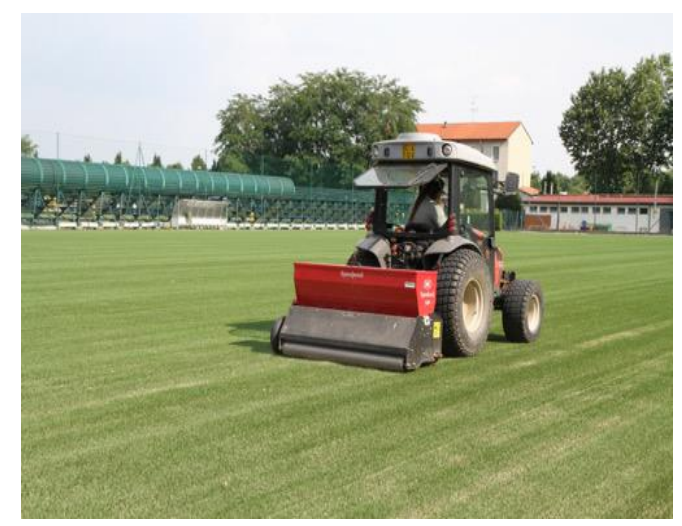

Şekil 9. Tohumlama Makinesi[19] 


\section{B. RULO HIBRIT ÇIM YÖNTEMI}

Rulo hibrit çim uygulamasında, daha önceden farklı bir alanda çimlendirilmiş[16] hibrit çim rulolarının(Şekil 10) uygulanacak alana getirilip serilmesiyle(Şekil 11) elde edilen uygulama yöntemidir. Bu yöntem diğer hibrit yöntemlerine nazaran daha maliyetli bir işlemdir[19].

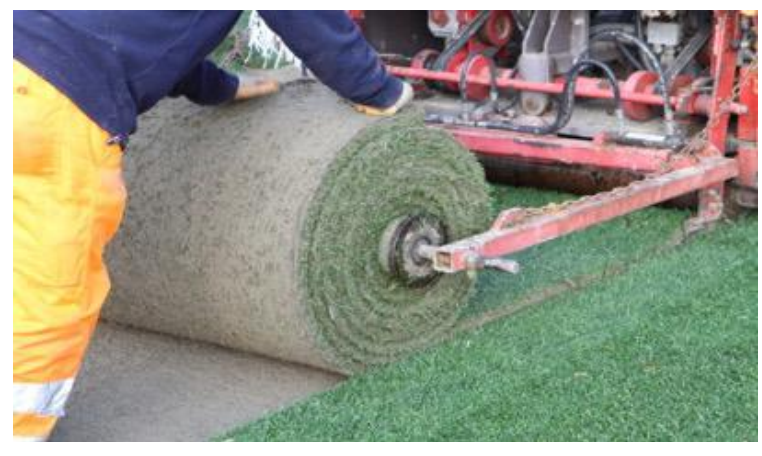

Şekil 10. Rulo Hibrit Çim[19]

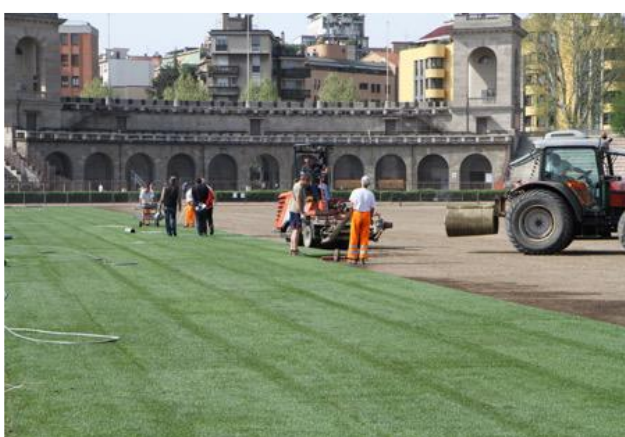

Şekil 11. Hibrit Rulo Çim Uygulaması [19]

\section{SONRADAN HIBRIT ÇIM YÖNTEMI}

Bu yöntem, doğal çim ile daha önceden tesis edilmiş saha üzerine dikiş makineleri(Şekil 11) aracılığıyla polipropilen olarak adlandırılan sentetik malzemenin yüzeyin yaklaşık $18-20 \mathrm{~cm}$. kadar olan kısmına çakılması(Şekil 12) ile gerçekleştirilmektedir[14]. Ülkemiz futbol takımlarından Beşiktaş J.K., resmi sahasında bu yöntemle elde edilen hibritleme işlemini tercih etmiştir.

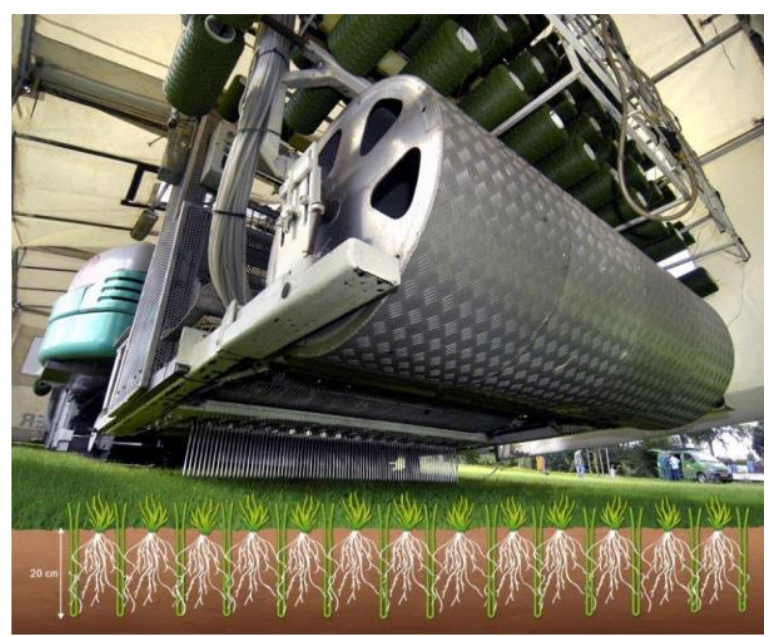

Şekil 12. Dikiş Makinesi [21]

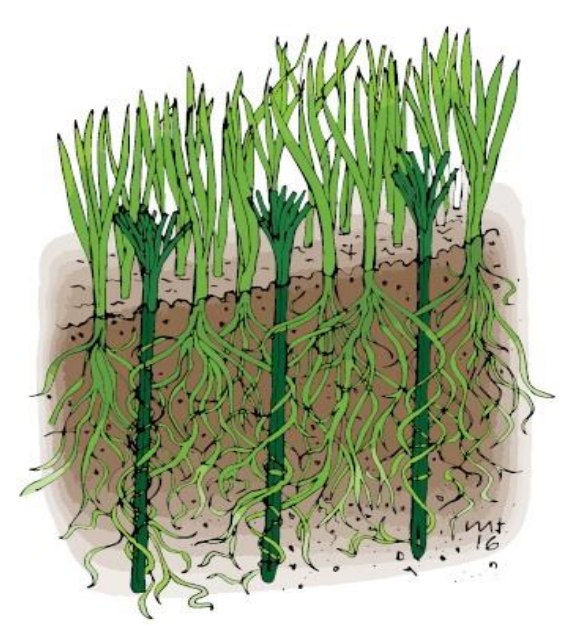

n 


\section{Hibrit Çim Uygulamasinin Dï̆̌̆er Çim Uygulama TeKNIKLERINE GÖRE AVANTAJLARI VE DEZAVANTAJLARI}

\section{A. AVANTAJLARI}

Dayanıklılık: Hibrit çim uygulaması ile tesis edilmiş alanlar, sentetik ve doğal çim dokusunun birlikte kullanılması nedeniyle $\% 100$ doğal çim yüzeylerden oluşturulmuş alanlara nazaran fiziksel olarak daha dayanıklıdır[20,21,22].

Çabuk Yenilenme: Sentetik lifler, oluşabilecek hasarlara karşı dayanıklı olduğundan doğal çimlere destek olmaktadırlar ve bu sayede çim yüzeyi az hasar almakta ve saha bir sonraki müsabaka için kendini daha çabuk yenileme avantajını elde etmektedir[22,23].

Yüksek Drenaj Kabiliyeti: Sentetik lifler toprağın sıkışma düzeyini azalttığından alanın drenaj kabiliyetini artırmada önemli rol oynamaktadır[11,22,23].

Düşük Bakım İsteği: Doğal çim zeminlerde iklimden dolayı y1l içinde değişiklikler görülürken, hibrit çim zeminler tutarlığını sürdürmektedirler[23]. Ayrıca müsabaka sırasında sentetik liflerin dayanım kabiliyeti sayesinde doğal çim doku daha az hasar almakta[16] ve bu sayede çim yüzeyin kendini yenileme süresi kısalmaktadır[11,22,23].

Esneklik: Sentetik liflerin basmalara karşı dayanımı ve çim kopmalarının asgari düzeyde yaşandığı bu alanlarda; sporun yanı sıra, gösteri ve konser gibi farklı organizasyonlara da ev sahipliği yapilabilmektedir[19].

Doğallık Hissi: 2000'li yıllarda saha zeminin yaklaşık \%80'i doğal çimden oluşmaktaydı[21]. Bu durum günümüzde ise çoğu alanda $\% 97$ doğal çim oranına yükselmiştir[18,23]. Bu durum da oyuncuların doğal çim alanda oynama hissiyatı açısından önemli görülmektedir.

Sık Kullanım Imkânı: Müsabaka sonrasında çim az hasar aldığından \%100 doğal çimden oluşmuş sahalara nazaran s1k kullanıma uygundur[23].

Kötü Kokunun Olmaması: Suni çimlerde bulunan kauçuk granüllerinin hibrit çim zeminlerinde bulunmaması nedeniyle hibrit çim yüzeyler sıcak hava koşullarında kötü kauçuk kokusunu barındırmamaktadır.

Kas Sakatlanmalarındaki Azalış: \%100 doğal çim zeminlere göre kas sakatlanmalarında azalış görülmektedir[17].

$\mathrm{Bu}$ durumlara ek olarak hibrit çim teknolojisi ile tesis edilmiş sahalarda, homojen renk dağılım devamlılığı sağlanmaktadır. Ayrıca zemine bağlı olumsuz oyun koşullarının daha düşük olmasından dolayı, hem izleyicilerin görsel kalite algısı artmakta hem de sporcular için elverişli müsabaka sahası koşullarını barındırmaktadırlar. 


\section{B. DEZAVANTAJLARI}

Kurulum Maliyeti Fazlalığı: \%100 doğal çim saha tesisine göre kurulum aşaması maliyeti fazladır[16].

Suni Çimden Oluşturulmuş Zemine Göre Bakım Maliyeti Fazlalı̆̆lı̣ Her ne kadar doğal çimden oluşturulmuş zeminlere göre bakım maliyeti az olsa da, suni çimden oluşturulmuş zeminlere göre bakım maliyeti fazladır.

Sulama Sıklı̆̆g Artışı: Güneş 1şınları, yapay malzeme tarafından doğal çim dokuya nazaran daha fazla tutulduğu için zemin sıcaklığında artış görülmektedir. Bu artışın etkisiyle zeminde daha fazla buharlaşma meydana gelmekte ve toprak daha geç soğumaktadır. Bu nedenle zeminin sulama sıklığı $\% 100$ doğal çimden oluşturulmuş zemine göre daha fazladır[24,25].

Bilek Sakatlanmalarındaki Artış: \%100 doğal çim sahalara göre futbolcular özelinde bilek sakatlanmalarında az da olsa bir miktar artış görülmektedir[17].

\section{SONUC}

Hibrit çim teknolojisi son zamanlarda futbol sahası tesisinde yoğun olarak tercih edilmektedir[11]. Dünya futbolunun önde gelen takımları hibrit çim yöntemiyle tesis edilmiş sahaları tercih etmektedirler. Oyun oynama zevkinin artması yanında, izleme zevki açısından da görsel kalite sunan bu alanlarda, dört mevsim müsabaka yapabilme olanağı sunulmaktadır. Hibrit çim teknolojisi sporcular için suni çimin yapaylık hissini yansıtmaması, zemine bağlı genel sakatlık riskinin az olması, yağmurlu müsabaka şartlarında drenaj kabiliyeti yüksekliğinden dolayı sahanın oyun veriminin yükselmesi ve doğal çim zeminin bakım isteklerinden kaynaklı sorunları barındırmaması nedeniyle son zamanlarda futbol sahalarında sıklıkla tercih edilmektedir. Her ne kadar diğer zeminlere göre daha yüksek maliyetle kurulumu yapılsa da; hibrit çim teknolojisi uygulanmış sahalar, sporcular için daha sağlıklı müsabaka sahası, seyirciler içinse toprağı yoğun bir şekilde kaplaması açısından yüksek görsel kalite anlamına gelmektedirler.

TEȘEKKÜR: Araştırma konusunda görsel kaynaklarını ve bilgilerini esirgemeyen MIXTO firmasına teşekkürlerimizi sunarız.

\section{KAYNAKLAR}

[1] C. Özşafak, F. Öner, “Çim Alan Tesisi ve Bakımı,” Peyzaj Uygulama ve Park Bahçe Bakımı Bahçıvanlık El Kitabı, 1.Baskı, İstanbul, Türkiye: Artus Basım, 2011, böl.7, ss. 479-498.

[2] H. Varoğlu, R. Avcıŏglu, R. Değirmenci, "Kamışsı Yumak (Festuca arundinaceae), Çayır Salkım Otu (Poa pratensis), Kırmızı Yumak (Festuca rubra) ve İngiliz Çimi (Lolium perenne) Çeşitlerinin Çim Alan Özellikleri," Tarla Bitkileri Merkez Araştırma Enstitüsü Dergisi, c. 24, s. 2, ss. 85-95, 2015. 
[3] S. Mutlu, C. Selim, "Sustainable Landscaping with Turfgrasses," Cumhuriyet Üni. Fen Fak. Fen Bilimleri Dergisi, c. 38, s. 2, ss. 188-190, 2017.

[4] R. Avcıoğlu, “Çim Tekniği Yeşil Alanların Ekimi Dikimi ve Bakımı”, İzmir, Türkiye: Ege Üniversitesi Matbaası, 1997, böl. 1, ss. 33-35.

[5] A. Kuşvuran, V. Tansı, "Çukurova Koşullarında Bazı Serin Mevsim Çim Bitkisi Tür ve Karışımlarının Çimlenme Süreleri ve Kaplama Hızlarının Belirlenmesi," Tarım Bilimleri Araştırma Dergisi, c. 6, s. 2, ss. 55-63, 2013.

[6] A. Talimciler, "Futbol İş Değil: Endüstriyel Futbol," İletişim Kuram ve Araştırma Dergisi, s.26, ss. 89-114, 2008.

[7] A. Ode, M. Tveit, G. Fry, "Capturing Landscape Visual Character Using Indicators: Touching Base with Landscape Aesthetic Theory,” Landscape Research, c. 33, s. 1, ss. 89-117, 2008.

[8] M. Davison, (2015, 14 Kasım). "Paying the price for the beautiful game?”, [Online]. Erişim: https://www.telegraph.co.uk/sport/football/11997637/Paying-the-price-for-the-beautiful game.html.

[9] V.H. Stiles, I.T. James, S.J. Dixon, I.N. Guissasola, "Natural Turf Surfaces The Case for Continued Research,” Sport Medicine, c.39, s.1, ss. 65-84, 2009.

[10] Anonim, (2017, May1s). "UEFA Congress Governance Reforms Adopted in Helsinki", [Online].Erişim:

https://www.uefa.com/MultimediaFiles/Download/EuroExperience/uefaorg/Publications/02/46/58/34/ 2465834_DOWNLOAD.pdf.

[11] F. Lulli, M. Volterrani, S. Magni, R. Armeni, "An Innovative Hybrid Natural-Artificial Sports Pitch Construction System," Proceedings of the Institution of Mechanical Engineers, Part P: Journal of Sports Engineering and Technology, s. 225, ss. 171-175, 2011.

[12] T.J. Serentsits, A.S. McNitt, D.M. Petrunak, "Human Health Issues on Synthetic Turf in the USA,"Proceedings of the Institution of Mechanical Engineers, Part P: Journal of Sports Engineering and Technology, s. 225, ss. 1-8, 2011.

[13] M. Crawford, (2017, Şubat), "New Artificial Turf Designs Improve Safety," [Online]. Erişim:https://www.asme.org/engineering-topics/articles/technology-and-society/new-artificial-turf designs-improve-safety-(2).

[14] A. Thomson, D. Rennie, "Evolution of Natural Grass Playing Surfaces for Elite Football," Aspetar Sport Medicine Journal, ss. 322-327, 2016.

[15] Anonim, (8 Şubat 2000). "New Kind of Artificial Turf As An Option in Unfavourable Climatic Conditions," [Online]. Erişim: https://football-technology.fifa.com/en/news/news-releases/new-kindof-artificial-turf-as-an-option-in-unfavourable-climatic-conditions/.

[16] B. Işık, "Hibrit Çim Yönteminin Futbol Sahalarında Uygulanırlığı," Hasan Kalyoncu Üni. Güzel Sanatlar ve Mimarlık Fak. Artium Dergisi, c. 5, s. 2, ss. 1-10, 2017. 
[17] Anonim, (14 Kasim 2014). "The total risk of injury is the same on football turf as it is on natural grass," [Online]. Erişim:

http://www.fifa.com/womensworldcup/news/y=2014/m=11/news=ekstrand-the-total-risk-of-injury-isthe-same-on-football-turf-as-it-i-2472281.html\#.

[18] Anonim, (26 Haziran 2017). "FIFA Quality Programme for Football Turf Handbook of Requirements," [Online]. Erişim: https://football-technology.fifa.com/media/1239/fqp-handbook-ofrequirements-v25.pdf.

[19] Anonim, (8 Mart 2018). Mixto Hybrid Grass Technology Brochure.

[20] F.D. Anderson, P. Fleming, P. Sherrratt, K. Severn, "Design and Development of a Novel Natural Turf Shear Stability Tester,” Procedia Engineering, c.147, ss. 842-847, 2016.

[21] M. Heinlein, "Advance in Hybrid Turf Systems," Technical Meeting of American Sports Builders Association, Florida, 2016.

[22] D. Rowaan, (2014, 10 Mart), "Hybrid grass, football, and soccer: Can it work?," [Online]. Erişim: https://www.wakingthered.com/2014/3/10/5482194/hybrid-grass-football-and-soccer-torontofc-bmo-field-argos.

[23] C. Andrews, (2016, 11 Ekim). "Hybrid football pitches: why the grass is always greener," [Online]. Erişim: https://eandt.theiet.org/content/articles/2016/10/hybrid-football-pitches-why-thegrass-is-always-greener/.

[24] T.J. Serentsits, A.S. McNitt, D.M. Petrunak, "Improving Surface Stability on Natural Turfgrass Athletic Fields," Proceedings of the Institution of Mechanical Engineers, Part P:Journal of Sports Engineering and Technology, s.225, ss. 85-92, 2011.

[25] R. Simon, "Review of the Impacts of Crumb Rubber in Artificial Turf Applications," University Of California Berkeley Laboratory For Manufacturing And Sustainability, ss. 1-59, 2010. 